\title{
Primary Headache and Silent Myocardial Ischemia in Patients with Coronary Artery Disease
}

\author{
Colomba Falcone ${ }^{a, b, d}$ Sara Bozzini ${ }^{a}$ Carmine Gazzaruso d, e \\ Margherita Calcagnino $^{a}$ Natascia Ghiotto $^{c}$ Rossana Falcone $^{a}$ \\ Adriana Coppola $^{e}$ Andrea Giustina $^{f}$ Gabriele Pelissero $^{b, d}$ \\ anterdepartmental Center of Research in Molecular Medicine, University of Pavia, ${ }^{b}$ Department of Cardiology, \\ Istituto Città di Pavia, University Hospital and ${ }^{\mathrm{C} H e a d a c h e ~ S c i e n c e ~ C e n t r e, ~ C . ~ M o n d i n o ~ N a t i o n a l ~ I n s t i t u t e ~ o f ~ N e u r o l o g y ~}$ \\ Foundation IRCCS, Pavia, dIRCCS San Donato Hospital, Milano, e Department of Internal Medicine, Diabetes, \\ Endocrine-Metabolic Diseases and Cardiovascular Prevention Unit and the Centre for Applied Clinical Research, \\ Clinical Institute 'Beato Matteo', Vigevano, and ${ }^{\mathrm{f}}$ Department of Internal Medicine, University of Brescia, Brescia, Italy
}

\section{Key Words}

Primary headache - Silent myocardial ischemia .

Coronary artery disease

\begin{abstract}
Objective: The mechanisms by which migraine is linked to ischemic vascular disease remain uncertain and are likely to be complex. The aim of this study was to investigate the correlation between silent myocardial ischemia (SMI) and a history of documented primary headache in a large population of patients with exercise-induced myocardial ischemia. Methods: The study involved 1,427 consecutive patients (918 symptomatic and 509 asymptomatic patients) with exercise-induced myocardial ischemia and documented coronary artery disease (CAD). Results: Patients with anginal symptoms during exercise-induced myocardial ischemia had a significantly higher prevalence of primary headache than those without ( 41 vs. $30 \%, p<0.001$ ). Patients with angina pectoris in daily life also had greater prevalence of primary headache than those without anginal symptoms (37 vs. $20 \%$;
\end{abstract}

$\mathrm{p}<0.0001)$. Symptomatic patients during percutaneous transluminal coronary angiography or myocardial infarction had a greater prevalence of primary headache than asymptomatic patients ( $p<0.001$ and $p=0.005$, respectively). Conclusions: Our data suggest that a history of headache in CAD population is correlated to a high probability of anginal symptoms and a decreased probability of SMI. The anamnestic absence of headache requires a close monitoring for patients with risk factors for $C A D$, because this population seems to have a lower susceptibility to pain and the risk of developing SMI might be increased.

Copyright $\odot 2013$ S. Karger AG, Basel

\section{Introduction}

Silent myocardial ischemia (SMI) is defined as an objective documentation of myocardial ischemia in the absence of angina or anginal equivalents [1].

According to the Cohn classification [2], SMI can occur in: (1) totally asymptomatic individuals without any

\section{KARGER}

E-Mail karger@karger.com

www.karger.com/crd
(C) 2013 S. Karger AG, Basel

0008-6312/13/1253-0133\$38.00/0
Colomba Falcone, M.D

Department of Cardiology

Istituito di Cura Città di Pavia, University Hospital

Via Parco Vecchio 27, IT-27100 Pavia (Italy)

E-Mail colomba.falcone@unipv.it 
evidence of known coronary artery disease (CAD), (2) subjects who are asymptomatic after having a myocardial infarction (MI) and (3) those with both symptomatic and asymptomatic ischemic episodes. Groups 2 and 3 can be merged so that group 1 consists of patients without known CAD and group 2 with known disease [3]. This latter group is at particularly high risk for cardiovascular events [4-6].

The presence or absence of anginal symptoms may be partly explained by individual differences in the pain threshold [7-9]. In addition, chemical factors released in response to ischemia which stimulate cardiac afferent pain fibers may be responsible for cardiac pain; various chemical agents have been implicated as a stimulus for angina pectoris during ischemia $[10,11]$. However, the mechanism underlying SMI is not well understood, and many theories have been advanced.

Headaches are most thoroughly classified by the International Headache Society's International Classification of Headache Disorders [12, 13], which divides headaches into two broad categories: primary headache disorders (which include migraine, tension-type and cluster headache) and secondary headache.

Some studies have explored the possible association between primary headache and CAD, especially in subjects with migraine [14-17]. In addition, migraine, especially with aura, is an established risk factor for ischemic lesions of the brain [18]. Recent evidence has linked migraine to a broader range of ischemic vascular disorders, including angina, MI, coronary revascularization, claudication and cardiovascular mortality [19]. The mechanisms by which migraine is linked to ischemic vascular disease remain uncertain and are likely to be complex. To the best of our knowledge, there are no data available in the literature regarding the association between primary headache and SMI. Therefore, the aim of this study was to explore whether the absence of anginal symptoms during myocardial ischemia was associated to reduced sensibility to pain. In particular, we investigate the possible correlation between SMI and a history of primary headache (migraine, tensiontype and cluster headache) in a large population of CAD patients with exercise-induced myocardial ischemia.

\section{Methods}

\section{Patient Selection}

This study included 1,427 consecutive patients (1,188 men and 239 women) who underwent both an exercise test and coronary angiography and presented the following characteristics: (1) exercise-induced myocardial ischemia (ischemic electrocardiographic response of horizontal or downsloping ST-segment depression of at least $0.1 \mathrm{mV}$ during exercise testing) and (2) angiographically documented significant CAD defined as the presence of greater than $50 \%$ narrowing of the luminal diameter of one or more coronary arteries.

Patients with pain syndrome or acute pain at the time of examination were excluded from the study as well as patients with cerebrovascular events, trauma or known cognitive, sensory and motor defects.

The study protocol conformed to the ethical guidelines of the Declaration of Helsinki. Informed written consent was obtained from all subjects and the study was approved by the ethical committee. The authors of this manuscript have certified that they comply with the principles of ethical publishing in the International Journal of Cardiology [20].

\section{Exercise Stress Test}

Exercise stress testing was performed as previously described [6]. Briefly, a multistage-bicycle-ergometer exercise stress test was performed with the patients in the supine position with an initial workload of $25 \mathrm{~W}$ and successive increments of $25 \mathrm{~W}$ every $3 \mathrm{~min}$ at a pedaling frequency of $60 \mathrm{rpm}$. A standard 12-lead electrocardiography was taken before, at the end of each stage and at the end of exercise. Leads V4, V5, V6 were monitored during exercise. The systolic and diastolic blood pressures were measured with a sphygmomanometer at basal conditions, at the end of each interval, at the maximum amount of work and every 3 min in the recovery phase. During the test, the patients were interrogated continuously regarding their symptoms in terms of pain, dyspnea, vertigo and tachycardia among others. Patients who always reported anginal symptoms were enrolled in the symptomatic group and those who did not complain of anginal pain were enrolled in the asymptomatic group. Patients with pace-maker, valvular disease or heart failure were excluded from the study.

The test was interrupted if one of these conditions manifested: fatigue, appearance of chest pain and/or dyspnea, exhaustion, STsegment elevation $\geq 1 \mathrm{~mm}$ without diagnostic Q waves, ST-segment depression $\geq 2 \mathrm{~mm}$, repetitive arrhythmias and a drop in systolic blood pressure $>10 \mathrm{~mm} \mathrm{Hg}$. The test was considered positive in the presence of downsloping ST-segment depression $\geq 1 \mathrm{mV}$ below the baseline, at least $0.06-0.08 \mathrm{~s}$ after the QRS complex Jpoint in multiple leads or ST-segment elevation.

Before the exercise test, pharmacological washout was performed. Calcium-channel antagonists and nitrates were halted $48 \mathrm{~h}$ before the test. $\beta$-Blockers were gradually reduced and then stopped 1 week before the examination. Patients who were taking digitalis were not included in this study.

\section{Cardiovascular Risk Factors}

Diabetes was diagnosed according to the American Diabetes Association criteria [21]. Hypertension was diagnosed according to the European Society of Hypertension/European Society of Cardiology criteria [22] or in the presence of a specific treatment. A family history of CAD was defined as documented evidence of premature CAD in a close relative (men $<55$ and women $<65$ years of age). Subjects were classified as currently smoking, as having smoked in the past (if they had stopped $>4$ weeks and $<40$ years earlier), or as never having smoked (if they had never smoked or had stopped $\geq 40$ years earlier). All patients completed the Perceived Stress Scale [23]. 
Coronary Angiography

All subjects underwent diagnostic coronary angiography using standard techniques, as previously described [6]. CAD was defined as angiographic evidence of stenosis in any epicardial coronary artery of $\geq 50 \%$ of its diameter. CAD extent was defined by the number of major epicardial coronary vessels with angiographic evidence of one or more stenosis of $\geq 50 \%$ severity.

\section{Ascertainment of Headache Status}

Trained interviewers asked participants about their lifetime history of headaches based on the criteria of the second edition of the International Headache Society's Classification of Headache Disorders which represents the most important document for the diagnosis and management of headache patients. This classification divides headaches into 3 categories: (1) primary, (2) secondary and (3) cranial neuralgias, facial pain and other headaches. In particular, we looked at the presence of tension-type, migraine or cluster headaches, which are the three most common forms of primary headache [13].

\section{Statistical Analysis}

The Kolmogorov-Smirnov test of normality was used to verify whether the distribution of variables followed a Gaussian pattern. Normally distributed data in groups were expressed as means \pm SDs. For continuous variables, the differences between the groups were evaluated with an unpaired Student $t$ test. To explore the independence between SMI and several variables, a multiple regression analysis was performed. Nonnormally distributed variables were log-transformed before the analyses. Categorical variables are presented by frequency counts, and intergroup comparisons were analyzed by a $\chi^{2}$ test. Two-tailed $\mathrm{p}<0.05$ was considered statistically significant.

\section{Results}

Table 1 shows clinical, biological and angiographic feature of the whole population with exercise-induced myocardial ischemia and patients stratified by the presence/ absence of anginal symptoms. Our study group consisted of 1,427 patients $(1,188$ men with a mean age of $59 \pm$ 9 years and 239 women with a mean age of $62 \pm 8$ years). Seven hundred patients (49\%) had a previous history of MI, 534 (37\%) had a history of percutaneous transluminal coronary angiography (PTCA) and 280 (19\%) had previously had surgical revascularization. All patients displayed exercise-induced myocardial ischemia: 918 (64\%) had chest pain during exercise (symptomatic group), while 509 (36\%) had SMI (asymptomatic group). Five hundred and twenty-nine (37\%) patients reported a history of primary headache and $106(20 \%)$ presented with migraine, $421(80 \%)$ had tension-type headache and 2 had cluster headache. The presence of symptoms during exercise-induced myocardial ischemia was similar in patients with migraine or tension-type headache.

Primary Headache and SMI in Patients with CAD
Table 1. Clinical, biological and angiographic feature of the whole population with myocardial ischemia and patients stratified by the presence/absence of anginal symptoms

\begin{tabular}{|c|c|c|c|}
\hline & $\begin{array}{l}\text { Study } \\
\text { population } \\
(\mathrm{n}=1,427)\end{array}$ & $\begin{array}{l}\text { Asymptomatic } \\
\text { patients } \\
(\mathrm{n}=509)\end{array}$ & $\begin{array}{l}\text { Symptomatic } \\
\text { patients } \\
(\mathrm{n}=918)\end{array}$ \\
\hline Men, n (\%) & $1,188(83)$ & $428(84)$ & $760(83)$ \\
\hline Age, years & $59 \pm 10$ & $59 \pm 8$ & $60 \pm 9$ \\
\hline \multicolumn{4}{|l|}{ Common risk factors, $\mathrm{n}(\%)$} \\
\hline Hypertension & $703(49)$ & $244(48)$ & $459(50)$ \\
\hline Dyslipidemia & $900(63)$ & $310(61)$ & $590(64)$ \\
\hline Diabetes & $513(36)$ & $163(32)$ & $350(38)$ \\
\hline Ever-smoking & $340(24)$ & $86(17)$ & $254(27)$ \\
\hline $\begin{array}{l}\text { Family history of } \\
\text { cardiovascular disease }\end{array}$ & $704(49)$ & $244(48)$ & $460(50)$ \\
\hline Stress & $677(47)$ & $219(43)$ & $458(50)$ \\
\hline \multicolumn{4}{|l|}{ History of primary headache } \\
\hline Headache history & $529(37)$ & $153(30)$ & $376(41)$ \\
\hline No history of headache & $898(63)$ & $356(70)$ & $542(59)$ \\
\hline
\end{tabular}

No differences in age, gender and common cardiovascular risk factors were observed between symptomatic and asymptomatic subjects (table 1). Patients with symptoms during exercise-induced myocardial ischemia had a significantly greater prevalence of primary headache than those without (41 vs. $30 \%$; $\mathrm{p}<0.001$ ).

\section{Multivariate Analysis}

To assess whether the association between primary headache and SMI was independent, a multiple regression analysis was performed with the following variables as potential predictors: hypertension, dyslipidemia, a positive family history of CAD, ever-smoking, stress, diabetes, BMI, age and medical treatment. In the multiple regression analysis, we found that primary headaches were independently associated with angina $(\beta=0.095$; $\mathrm{p}<0.001)$.

\section{Subgroup Analysis}

Diabetic patients who had chest pain during the exercise-stress test had a greater prevalence of primary headache than asymptomatic diabetic patients (45 vs. $27 \%$; $\mathrm{p}=0.002$ ). Likewise, in symptomatic hypertensive patients, the prevalence of primary headache was greater than in asymptomatic hypertensive patients ( 44 vs. $27 \%$; $\mathrm{p}<0.0001)$.

We also analyzed the correlation between a history of primary headache and episodes of anginal symptoms during daily life, PTCA and MI as shown in figure 1 . The presence of a history of primary headache was greater in 


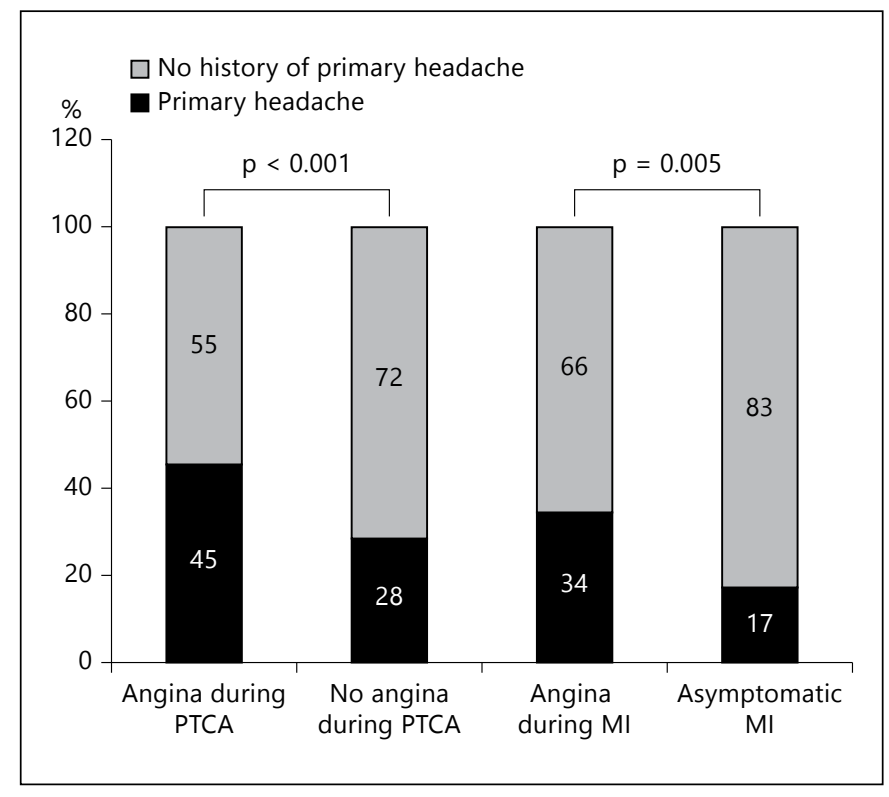

Fig. 1. Distribution of primary headache in patient with and without anginal symptoms during PTCA and MI.

patients with a history of angina in daily life than in patients without angina ( 37 vs. $20 \%$; $p<0.0001$ ). Of the 534 patients that underwent PTCA, 236 (44\%) reported anginal symptoms during the procedure and 301 (56\%) reported none. Symptomatic patients during PTCA had a greater prevalence of primary headache than asymptomatic patients ( 28 vs. $45 \%$; p < 0.001 ). Finally, of the 700 patients with previous MI, 635 (89\%) had angina during the event, while 217 (34\%) did not; in this subgroup, the prevalence of primary headache was higher in the symptomatic patients than in the asymptomatic patients ( $34 \mathrm{vs}$. $17 \% ; \mathrm{p}=0.005)$.

\section{Discussion}

This study on a large CAD population suggests that the presence of primary headache could be a useful marker to identify subjects with susceptibility to pain and that its absence could be correlated with SMI. In our population, $34 \%$ of patients with CAD had a history of primary headache and, in particular, patients with anginal symptoms during the exercise-stress test had a higher prevalence of headache history than asymptomatic patients. This association was present also in the subgroups of hypertensive and diabetic patients and was confirmed by a multivariate analysis. Moreover, a history of primary headache was associated with the presence of referred pain during previous acute MI and/or during PTCA procedures. Taken together, our data suggest that symptomatic patients with primary headache were more prone to pain; this population differs from those with SMI and without headache in their reactivity to pain, confirmed to be a generalized hyposensitivity.

Recent evidence has linked migraine, in particular migraine with aura, to a broader spectrum of ischemic vascular disorders including coronary disease [24-26]. Several factors have been related to the absence of symptoms during myocardial ischemia, but the precise mechanisms responsible for the lack of pain have not yet been fully elucidated [1, 7-9]. Several studies have shown that in patients with SMI, the threshold of pain perception and tolerance are significantly higher than in symptomatic patients [8,27]. Granot et al. [27] demonstrated that the absence of pain in acute MI was associated with attenuated pain perception in response to various stimuli, and enhanced pain scores were reported in the MI patients with pain compared to those without pain. On the other hand, the onset of headache is widely attributed to a state of hypersensitivity to pain [28]. Therefore, in patients with SMI, the pain threshold was higher than in symptomatic patients, indicating altered systemic modulation of the pain threshold in SMI $[8,29]$. However, no previous studies have used the presence/ absence of headache to evaluate the pain threshold of SMI patients.

The correlation between primary headaches (especially migraine) and ischemic heart disease has been investigated, but results are still inconclusive [19, 29]. A recent study showed that patients with a history of migraine and other types of headache more commonly have a history of anginal symptoms $[28,29]$. As confirmation, a higher prevalence of anginal symptoms has been shown in patients with migraine [17].

In patients with CAD, the correlation between the absence of symptoms during exercise-induced myocardial ischemia and a history negative for headache seems to confirm a generalized hyposensitivity to pain.

Recently, the involvement of intracortical inhibitory circuits was proposed for migraine and an important role in the pathophysiology of headache chronification was proposed for the increase in cortical excitability [30].

A possible role of endogenous endorphins in response to pain has been extensively studied; some studies have suggested a correlation between low levels of endogenous endorphins and anginal symptoms [7, 31, 32], and between low endorphins levels and headache [33]. 
But above all, an important role in response to pain seems to be played by inflammatory substances [34], also implicated in the genesis, progression and clinical manifestations of CAD. In fact, some studies show the presence of anti-inflammatory cytokine pattern in patients with SMI $[35,36]$. A certain pattern of anti-inflammatory cytokines may be responsible for the lack of symptoms in patients with SMI; in particular, it is known that some inflammatory cytokines can induce the release of pain mediators such as bradykinin and calcitonin gene-related peptide and activate vagal afferent [37].

One of the most recent hypotheses is linked to the fact that these substances induce an increase of nitric oxide (NO) synthase. An increase of NO has been shown in patients with headache, and it seems that high concentrations of NO are responsible for changes in the presynaptic membrane receptor [38]. However, this role of NO is still controversial and the underlying mechanisms are still poorly understood. For this reason, a role could be played by the opioid system: in a study of patients with chronic tension-type headache, lower levels of Met-enkephalins have been highlighted, confirming their role in influencing the modulation of pain [39].

This pathophysiological mechanism might represent a common denominator between the presence/absence of anginal symptoms and of headache. It is possible to speculate, due to the importance of inflammation in the genesis of atherosclerotic plaque, that the endogenous opioids which derive from local immune cells interact with specific receptors on sensory nerves, leading to strong and clinically measurable analgesia $[34,40]$. Similarly, these data seem to confirm that individual differences in pain perception play an important role in the genesis of SMI and, more generally, in determining susceptibility to pain.

The clinical implications of our study may be of interest. Indeed, our data confirm the hypothesis of a generalized hyposensitivity to pain in patients with SMI, who are less susceptible, not only to angina, but also to headache. An interesting aspect of our clinical research indicates that, in patients with documented CAD or at a high risk for $\mathrm{CAD}$ who experience headache, there is a greater tendency to experience anginal symptoms: this exposes this population to a lower risk of asymptomatic ischemic episodes. Conversely, for those patients at a high risk for $\mathrm{CAD}$ and no history of headache, closer clinical observation is required because the higher prevalence of asymptomatic episodes may put them at increased risk for ischemic events or death.

The symptom headache in a population with risk factors for CAD might be somehow 'reassuring' because, according to our data, the occurrence of myocardial ischemia in such population is highly likely to manifest with anginal symptoms. On the other hand, the absence of episodes of headache in a population with risk factors for CAD might suggest a general hyposensitivity to pain. We speculate that such population might have an increased tendency to develop SMI.

In conclusion, our data suggest that the presence of headache in patients with known CAD decreases the probability of their having SMI, whereas the absence of headache recommends a close monitoring for those patients with risk factors for CAD, because in these patients, the risk of developing SMI might be increased. More investigations of a specific nature are needed to clarify this relationship.

\section{References}

1 Gutterman DD: Silent myocardial ischemia. Circ J 2009;73:785-797.

2 Cohn PF: A new look at benefits of drug therapy in silent myocardial ischaemia. Eur Heart J 2007;28:2053-2054.

3 Cohn PF, Fox KM, Daly C: Silent myocardial ischemia. Circulation 2003;108:1263-1277.

4 Gottlieb SO, Gottlieb SH, Achuff SC, Baumgardner R, Mellits ED, Weisfeldt ML, Gerstenblith G: Silent ischemia on Holter monitoring predicts mortality in high-risk postinfarction patients. JAMA 1988;259:1030-1035.

$\checkmark 5$ Ouyang P, Chandra NC, Gottlieb SO: Frequency and importance of silent myocardial ischemia identified with ambulatory electrocardiographic monitoring in the early inhospital period after acute myocardial infarction. Am J Cardiol 1990;65:267-270.
6 Falcone C, de Servi S, Poma E, Campana C, Sciré A, Montemartini C, Specchia G: Clinical significance of exercise-induced silent myocardial ischemia in patients with coronary artery disease. J Am Coll Cardiol 1987; 9:295-299.

$\checkmark 7$ Falcone C, Specchia G, Rondanelli R, Guasti L, Corsico G, Codega S, Montemartini C: Correlation between beta-endorphin plasma levels and angina symptoms in patients with coronary artery disease. J Am Coll Cardiol 1988; 11:719-723.

8 Falcone C, Sconocchia R, Guasti L, Codega S, Montemartini C, Specchia G: Dental pain threshold and angina pectoris in patients with coronary artery disease. J Am Coll Cardiol $1988 ; 12: 348-352$.
-9 Glazier JJ, Chierchia S, Brown MJ, Maseri A Importance of generalized defective perception of painful stimuli as a cause of silent myocardial ischemia in chronic stable angina pectoris. Am J Cardiol 1986;58:667-672.

10 Meller ST, Gebhart GF: A critical review of the afferent pathways and the potential chemical mediators involved in cardiac pain. Neuroscience 1992;48:501-524.

11 Ammons WS, Blair RW, Foreman RD: Vagal afferent inhibition of spinothalamic cell responses to sympathetic afferents and bradykinin in the monkey. Circ Res 1983;53:603-612.

12 Classification and diagnostic criteria for headache disorders, cranial neuralgias and facial pain. Headache Classification Committee of the International Headache Society. Cephalalgia 1988;7:1-96.
Primary Headache and SMI in Patients with CAD 
13 The International Classification of Headache Disorders, ed 2. Cephalalgia 2004;24(suppl 1): 9-160.

$\checkmark 14$ Winsvold BS, Hagen K, Aamodt AH, Stovner LJ, Holmen J, Zwart JA: Headache, migraine and cardiovascular risk factors: the HUNT study. Eur J Neurol 2011;18:504-511.

15 Kurth T, Schürks M, Logroscino G, Buring JE: Migraine frequency and risk of cardiovascular disease in women. Neurology 2009;73: 581-588.

16 Kurth T, Gaziano JM, Cook NR, Bubes V, Logroscino G, Diener HC, Buring JE: Migraine and risk of cardiovascular disease in men. Arch Intern Med 2007;167:795-801.

$\checkmark 17$ Scher AI, Terwindt GM, Picavet HS, Verschuren WM, Ferrari MD, Launer LJ: Cardiovascular risk factors and migraine: the GEM population-based study. Neurology 2005;64:614620.

18 Bigal ME: Migraine and cardiovascular disease. Arq Neuropsiquiatr 2011;69:122-129.

19 Bigal ME, Kurth T, Hu H, Santanello N, Lipton RB: Migraine and cardiovascular disease: possible mechanisms of interaction. Neurology 2009;72:1864-1871.

20 Coats AJS, Shewan LG: Statement on authorship and publishing ethics in the International Journal of Cardiology. Int J Cardiol 2011; 153:239-240.

-21 The Expert Committee on the Diagnosis and Classification of Diabetes Mellitus: Report on the diagnosis and classification of diabetes mellitus. Diabetes Care 1997;20:1183-1197.

-22 Mancia G, De Backer G, Dominiczak A, Cifkova R, Fagard R, Germano G, Grassi G, Heagerty AM, Kjeldsen SE, Laurent S, Narkiewicz K, Ruilope L, Rynkiewicz A, Schmieder RE, Boudier HA, Zanchetti A: 2007 ESHESC Practice Guidelines for the Manageme- nt of Arterial Hypertension: ESH-ESC Task Force on the Management of Arterial Hypertension. J Hypertens 2007;25:1751-1762.

23 Cohen S, Kamarck T, Mermelstein R: A global measure of perceived stress. J Health Soc Behav 1983;24:386-396.

24 Kurth T, Gaziano JM, Cook NR, Logroscino G, Diener HC, Buring JE: Migraine and risk of cardiovascular disease in women. JAMA 2006;296:283-291.

25 Rose KM, Carson AP, Sanford CP, Stang PE, Brown CA, Folsom AR, Szklo M: Migraine and other headaches: associations with Rose angina and coronary heart disease. Neurology 2004;63:2233-2239.

26 Rose KM, Wong TY, Carson AP, Couper DJ, Klein R, Sharrett AR: Migraine and retinal microvascular abnormalities: the Atherosclerosis Risk in Communities Study. Neurology 2007;68:1694-1700.

27 Granot M, Khoury R, Berger G, Krivoy N, Braun E, Aronson D, Azzam ZS: Clinical and experimental pain perception is attenuated in patients with painless myocardial infarction. Pain 2007;133:120-127.

28 Glusman M, Coromilas J, Clark WC, Janal MN, Blood DK, Kuhl JP, Burns K: Pain sensitivity in silent myocardial ischemia. Pain 1996;64:477-483.

29 Bendtsen L: Pain sensitivity in children with frequent episodic tension type headache. Cephalalgia 2010;30:1029-1030.

30 Coppola G, Schoenen J: Cortical excitability in chronic migraine. Curr Pain Headache Rep 2012;16:93-100.

31 Falcone C, Guasti L, Ochan M, Specchia G, Montemartini C: Beta-endorphins during coronary angioplasty in patients with silent or symptomatic myocardial ischemia. J Am Coll Cardiol 1993;22:1614-1620.
32 Sadigh B, Berglund M, Fillingim RB, Sheps D, Sylvén C: $\beta$-Endorphin modulates adenosineprovoked chest pain in men, but not in women - a comparison between patients with ischemic heart disease and healthy volunteers. Clin J Pain 2007;23:750-755.

33 Fettes I, Fox J, Kuzniak S, Shime J, Gare D: Plasma levels of immunoreactive beta-endorphin and adrenocorticotropic hormone during labor and delivery. Obstet Gynecol 1984; 64:359-362.

34 Abrahamsen B, Zhao J, Asante CO, Cendan CM, Marsh S, Martinez-Barbera JP, Nassar MA, Dickenson AH, Wood JN: The cell and molecular basis of mechanical, cold, and inflammatory pain. Science 2008;321:702-705.

35 Mazzone A, Cusa C, Mazzucchelli I, Vezzoli M, Ottini E, Pacifici R, Zuccaro P, Falcone C: Increased production of inflammatory cytokines in patients with silent myocardial ischemia. J Am Coll Cardiol 2001;38:1895-1901.

36 Tedgui A, Mallat Z: Cytokines in atherosclerosis: pathogenic and regulatory pathways. Physiol Rev 2006;86:515-581.

37 Dray A: Inflammatory mediators of pain. Br J Anaesth 1995;75:125-131.

38 Ashina M, Bendtsen L, Jensen R, Olesen J: Nitric oxide-induced headache in patients with chronic tension-type headache. Brain 2000; 123:1830-1837.

-39 Langemark M, Bach FW, Ekman R, Olesen $\mathrm{J}$ : Increased cerebrospinal fluid Met-enkephalin immunoreactivity in patients with chronic tension-type headache. Pain 1995; 63:103-107.

40 Mazzone A, Ricevuti G, Pasotti D, Fioravanti A, Marcoli M, Lecchini S, Notario A, Frigo GM: Peptide opioids and morphine effects on inflammatory process. Inflammation 1990;14: 717-726. 